\title{
An Integrated Procedure for the Structural Design of a Composite Rotor-Hydrofoil of a Water Current Turbine (WCT)
}

\author{
S. A. Oller Aramayo • L. G. Nallim • S. Oller
}

Received: 29 June 2013 / Accepted: 2 July 2013 / Published online: 25 July 2013

(C) Springer Science+Business Media Dordrecht 2013

\begin{abstract}
This paper shows an integrated structural design optimization of a composite rotor-hydrofoil of a water current turbine by means the finite elements method (FEM), using a Serial/Parallel mixing theory (Rastellini et al. Comput. Struct. 86:879-896, 2008, Martinez et al., 2007, Martinez and Oller Arch. Comput. Methods. 16(4):357-397, 2009, Martinez et al. Compos. Part B Eng. 42(2011):134-144, 2010) coupled with a fluid-dynamic formulation and multi-objective optimization algorithm (Gen and Cheng 1997, Lee et al. Compos. Struct. 99:181-192, 2013, Lee et al. Compos. Struct. 94(3):1087-1096, 2012). The composite hydrofoil of the turbine rotor has been design using a reinforced laminate composites, taking into account the optimization of the carbon fiber orientation to obtain the maximum strength and lower rotational-inertia. Also, these results have been compared with a steel hydrofoil remarking the different performance on both structures. The mechanical and geometrical parameters involved in the design of this fiber-reinforced composite material are the fiber orientation, number of layers, stacking sequence and laminate thickness. Water pressure in the rotor of the turbine is obtained from a coupled fluid-dynamic simulation (CFD), whose detail can be found in the reference Oller et al. (2012). The main purpose of this paper is to achieve a very low inertia rotor minimizing the start-stop effect, because it is applied in axial water flow turbine currently in design by the authors, in which is important to take the maximum advantage of the kinetic energy. The FEM simulation codes are engineered by CIMNE (International Center for Numerical Method in Engineering, Barcelona, Spain), COMPack for the solids problem application, KRATOS for fluid dynamic application and RMOP for the structural optimization. To validate the procedure here
\end{abstract}

S. A. Oller Aramayo • L. G. Nallim

INIQUI - CONICET - Faculty of Engineering, National University of Salta

Av. Bolivia 5150, Salta, Argentina

S. A. Oller Aramayo

e-mail: sergio.oller@conicet.gov.ar

L. G. Nallim

e-mail: lnallim@unsa.edu.ar

S. Oller $(\bowtie)$

UPC-CIMNE-International Center for Method in Engineering, UPC, Technical University of Catalonia (Barcelona Tech), c/Jordi Girona 1-3, 08034 Barcelona, Spain

e-mail: sergio.oller@upc.edu 
presented, many turbine rotors made of composite materials are analyzed and three of them are compared with the steel one.

Keywords Water current turbines (WCT) - Composite materials $\cdot$ Rotor turbine design and analysis $\cdot$ Finite element method (FEM) $\cdot$ Multi-objective Optimization

\section{Introduction}

Water Current Turbines (WCT) are an important topic of study at present, because of the concept of using the most powerful and predictable renewable energy (current water), without modifying the environment. In this particular case the studied rotor belongs to an axial riverbed WCT designed by the authors (Fig. 1) [1]. Its compact design, its condition of axial flow and its low rotational inertia due to the composite material rotors, confer the functionality at low speed fluvial beds, avoiding the requirement of great earthworks and expensive civil constructions.

Multi-laminated composite structures are an ever-increasingly important topic in the fields of fabrication of mechanical, aerospace, marine, and machinery industries due to their advantages such as durability (no corrosion-lower maintenance cost), survivability (fire resistance, crash energy absorption), excellent resistance against cyclic loading (low fatigue), reparability (restoration and repair), etc. Multilayered fiber-reinforced material systems can offer versatility in composite design due to the fact that the stacking sequence of each orthotropic Iayer can take full advantage of the superior meehanieal properties in terms of its strength,
stiffness, and total weight. Ond of the goals in design optimization of multilayered composite
structure is to increase its strength while 1 wering its weight/rotational inertia with a given set of
fibrous materials. Laminate of fiber-reinforced composites are very useful when low weight/rotational inertia together high strength/stiffness are required, like the case of axial

Register for free at https/WWW. WCIpedia.com to downlogd the version without the watermark efficiency through the design of the fiber orientation, fraction reinforcement volume, choice of large or short fibers, layer thickness and stacking sequence.

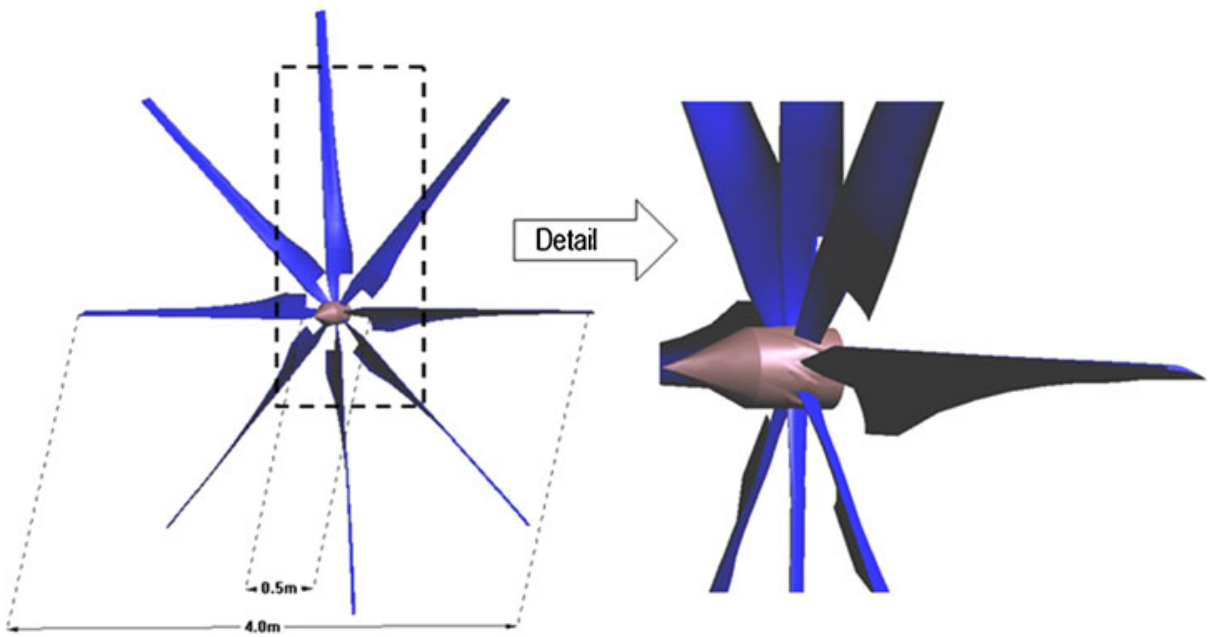

Fig. 1 Author's axial riverbed rotor of Water Current Turbine 
This paper studies the structural performance of a turbine rotor made-up of a laminate of fiberreinforced composites material using the mixing anisotropic theory. This formulation manages several damage constitutive models simultaneously and its homogenized damage composite variables, defining the inelastic limit behavior taking into account the reinforced of the matrix and the fiber-matrix debounding effect. The composite material used is a laminate composed by epoxy matrix reinforced with carbon fibers. The variations of the angle of fibers orientation and the thickness and stacking sequence are controlled by the Multi-objective Optimization module, allowing obtaining better values of stiffness and strength with a smaller weight and rotationalinertia. The anisotropic mixing theory has been implemented for the structural analysis on "COMPack" FEM explicit code [2-5] coupled with "KRATOS" [6] fluid dynamic FEM code, and the above mentioned optimization module. These codes (see Fig. 2) allows the fiberreinforced composites rotor design takes into account the successive geometric and mechanical changes of each component materials that forming the composite. The finite elements code for the study of the behavior of the fluid-dynamic problem of the rotor (KRATOS Multi-Physics [6]) give the state of pressures and speeds of the fluid in each point of the rotor blades [1]. Although in this work the structural analysis of the turbine rotor is mainly shown, the achievement of such results has been possible thanks to the coupling between both codes, COMPack-FEM and KRATOS-FEM (Fig. 2). Details about this fluid dynamic numerical simulation are available at the reference Oller et al. [1]. Thus, the fluid pressures and speeds distribution in the axial camera of the turbine obtained by means the KRATOS-FEM code, are introduced to the COMPack-FEM code (here reported) by a "staggered" procedure [7, 8], solving each problem per time (Fig. 2).

To conclude the influence of the fiber direction and layers configuration in the composite

f the turbine rotor proposed in

hydrofoil constituted by

onfigurations $\left( \pm 45^{\circ}\right.$,

them and with those 0
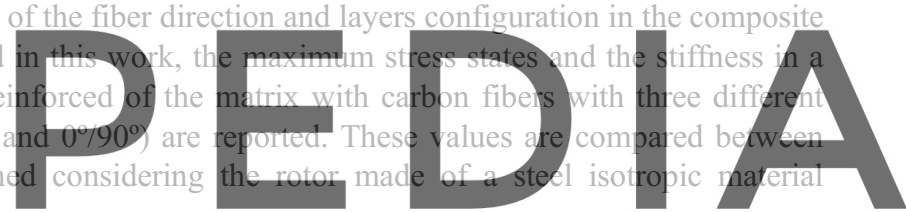

Register for free at https//www.scipedia.compto download the version without the watermark

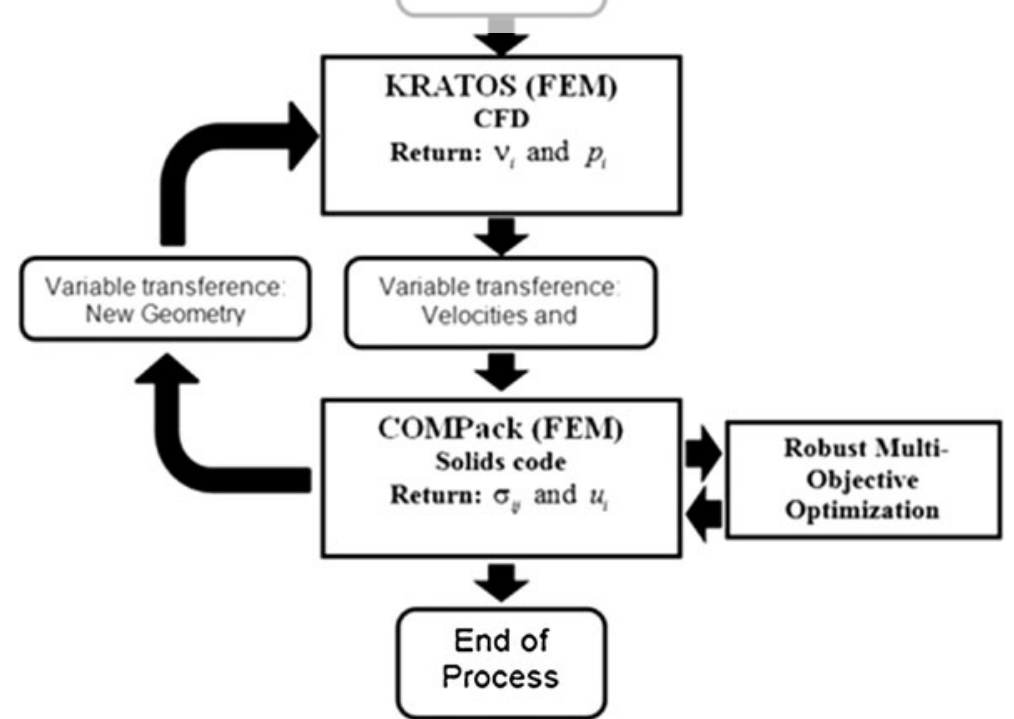

Fig. 2 Flow diagram of solid-fluid Finite Element Program interaction 
(Fig. 7). The numerical simulation of the hydrofoil of composite material is obtained using a formulation based on the generalized anisotropic theory of mixtures [3, 9].

\section{Numerical Model for the Structural Design of a Turbine Rotor Made of a Laminate of Fiber-Reinforced Composite}

This section presents the proposed constitutive model for the turbine rotor hydrofoil design on epoxy matrix reinforced with carbon fibers. For this purpose a summary of the constitutive damage model $[5,10,11]$ managed by an orthotropic Serial/Parallel mixing theory $[3,5,10$, 12 ] coupled with an optimal multi-objective genetic algorithm design [13,14] are introduced in this paper. The coupling of these numerical models provides a laminate safety factor obtained from a new definition of homogenized laminate damage index which is obtained from the local damage provided by the constitutive damage model previously mentioned.

A stacking sequence and carbon fiber orientation design optimization for multilayered composite blade is made-up using an evolutionary algorithm [13, 14]. The stacking sequence and orientation of fibers has a strong influence on the strength of multilayered composite blades. Multiple layers of fiber-reinforced material systems offer flexibility in engineering material design, offering several types of composite materials with the best mechanical properties. Numerical results show that optimal composite turbine rotor designed has a lower rotational-inertia, higher stiffness and also affordable cost when compared with other solutions, included the classical steel hydrofoils.

Next sections present a summary of the proposed mechanical formulation used in this paper:

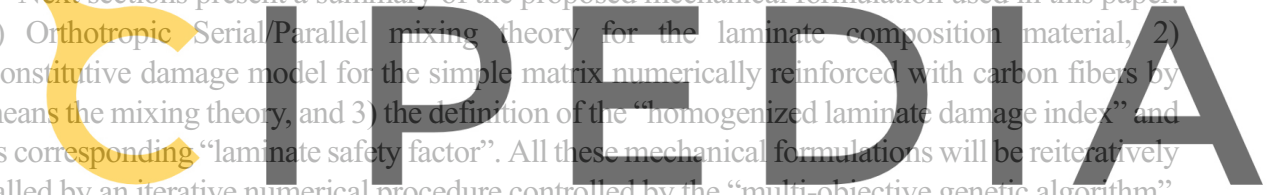

called by an iterative numerical procedure controlled by the "muiti-objective genetic algorithm",

that will provide a well-desioned composite rotor after a finite number of iteration.

Register for free at https//Www.scipedia.com to download the version without the watermark

\subsection{Serial/Parallel Mixing Theory for One Layer}

The classical rule of mixtures, originally developed by Trusdell and Toupin, $[4,9,15,16]$, uses a phenomenological approach based on continuum mechanics in the macro-scale for the composite mechanical analysis. The main problem of classical mixing theory is the poor ability to represent the serial behavior of the components in the composite (Fig. 3, iso-stress case).

The serial/parallel rule of mixtures improves the classical mixing theory replacing the isostrain hypothesis for an iso-strain condition in the fiber direction and an iso-stress condition in the transversal one (Eq. (6)). This allows modeling all the components distribution in the composite as shown in Fig. 3. This formulation is an alternative to the homogenization technique, based on the multiple scale study [17, 18]. An extensive description of this formulation can be found in Rastellini, [3].

The serial/parallel (SP) model [3] considers that the component materials of the composite act in parallel along a certain direction and in serial in the remaining directions. Consequently, it is necessary to define and separate the serial and parallel components of the strain and stress tensors. Defining $\boldsymbol{e}_{1}$ as the director vector that determines the parallel behavior (fiber direction), the parallel projector tensor $N_{P}$ can be defined as

$$
\boldsymbol{N}_{P}=\boldsymbol{e}_{1} \otimes \boldsymbol{e}_{1}
$$



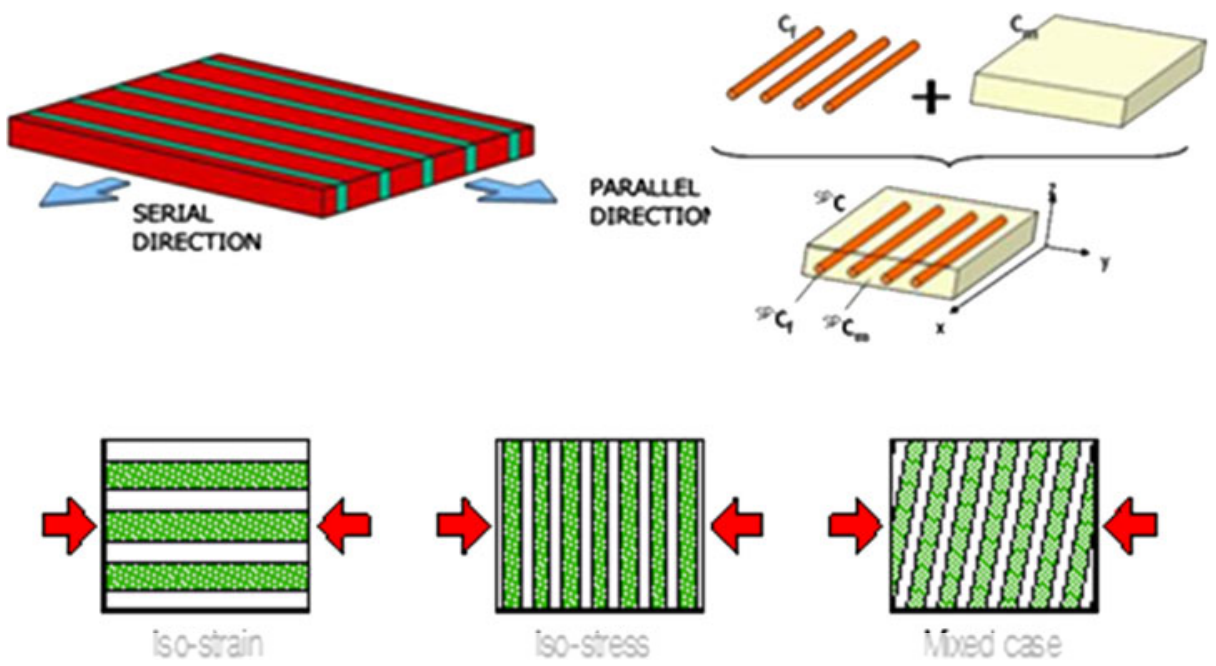

Fig. 3 Different distribution of components in a composite material

Using $\boldsymbol{N}_{P}$, the 4th-order parallel projector tensor $\boldsymbol{P}_{P}$, and the complementary serial projector tensor $\boldsymbol{P}_{S}$, are defined as:
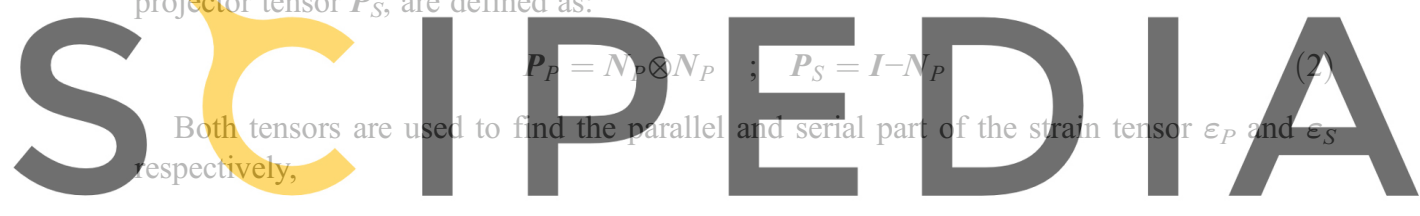

$\varepsilon_{P}=\boldsymbol{P}_{P}: \varepsilon$

$\varepsilon_{S}=\boldsymbol{P}_{S}: \varepsilon$

(3)

Register for free at https//www.scipedia.com to download the version without the watermark

Hence, the strain and stress tensors are split into its parallel and serial parts

$$
\varepsilon=\varepsilon_{P}+\varepsilon_{S} \quad ; \quad \boldsymbol{\sigma}=\boldsymbol{\sigma}_{P}+\boldsymbol{\sigma}_{S} \quad ; \quad \text { where }: \boldsymbol{\sigma}_{P}=\boldsymbol{P}_{P}: \boldsymbol{\sigma} \text { and } \boldsymbol{\sigma}_{S}=\boldsymbol{P}_{S}: \boldsymbol{\sigma}
$$

The main hypothesis in which the numerical model of the Serial/Parallel mixing theory is based are: (i) the composite is composed by two component materials: fiber and matrix; (ii) the component materials have the same strain in parallel (fiber) direction; (iii) the component materials have the same stress in the serial direction; (iv) the composite material response is in direct relation with the volume fractions of the compounding materials; (v) the homogeneous distribution of phases is considered in the composite; (vi) perfect bounding between components is assumed.

The equations that define the stress equilibrium and establish the strain compatibility between components are obtained from the analysis of the model hypothesis. Thus,

$$
\begin{aligned}
& \text { Parallel behavior: }{ }^{c} \varepsilon_{P}={ }^{m} \varepsilon_{P}={ }^{f} \varepsilon_{P} \\
& { }^{c} \boldsymbol{\sigma}_{P}={ }^{m} k^{m} \boldsymbol{\sigma}_{P}+{ }^{f} k^{f} \boldsymbol{\sigma}_{P} \\
& \text { Serial behavior : }{ }^{c} \varepsilon_{S}={ }^{m} k^{m} \varepsilon_{S}+{ }^{f} k^{f} \varepsilon_{S} \\
& { }^{c} \boldsymbol{\sigma}_{S}={ }^{m} \boldsymbol{\sigma}_{S}={ }^{f} \boldsymbol{\sigma}_{S}
\end{aligned}
$$

where, $\varepsilon_{P}$ and $\varepsilon_{S}$ are the parallel and serial components of the stress tensor respectively, $\sigma_{P}$ and $\sigma_{S}$ are the parallel and serial components of the strain superscripts, $c, m$ and $f$ denote the 
composite, matrix and fiber materials and ${ }^{m} k$ and ${ }^{f} k$ are the volumetric participation of fiber and matrix in the composite, respectively.

The serial/parallel mixing theory can use any constitutive equation to describe the behavior of each component material. The constitutive equations chosen can be different for each component (for example, an elastic law to describe the fiber behavior and a damage formulation to describe the matrix behavior). The constitutive equations for the matrix and the fiber can be expressed as:

$$
{ }^{k} \boldsymbol{\sigma}={ }^{k} \mathbb{C}^{S}: \quad{ }^{k} \varepsilon \quad \text { where } \quad\left[\begin{array}{l}
{ }^{k} \sigma_{P} \\
{ }^{k} \sigma_{S}
\end{array}\right]=\left[\begin{array}{ll}
{ }^{k} \mathbb{C}_{P P}^{S} & { }^{k} \mathbb{C}_{P S}^{S} \\
{ }^{k} \mathbb{C}_{S P}^{S} & { }^{k} \mathbb{C}_{S S}^{S}
\end{array}\right]:\left[\begin{array}{l}
{ }^{k} \varepsilon_{P} \\
{ }^{k} \varepsilon_{S}
\end{array}\right]
$$

where ${ }^{k} \boldsymbol{\sigma}$ is the stress tensor of the $k$ th component material, ${ }^{k} \varepsilon$ is the total strain tensors, $\mathbb{C}$ is the respective damaged secant constitutive tensor and its elements are: ${ }^{k} \mathbb{C}_{P P}=\boldsymbol{P}_{P}$ : ${ }^{k} \mathbb{C}: \boldsymbol{P}_{P} ;{ }^{k} \mathbb{C}_{P S}=\boldsymbol{P}_{P}:{ }^{k} \mathbb{C}: \boldsymbol{P}_{S} ;{ }^{k} \mathbb{C}_{S P}=\boldsymbol{P}_{S}:{ }^{k} \mathbb{C}: \boldsymbol{P}_{P} ;{ }^{k} \mathbb{C}_{S S}=\boldsymbol{P}_{S}:{ }^{k} \mathbb{C}: \boldsymbol{P}_{S}$.

The schematic $\mathrm{S} / \mathrm{P}$ (or Generalized) Mixing Theory flow diagram implemented in the COMPack-FEM code, is shown in Fig. 4.

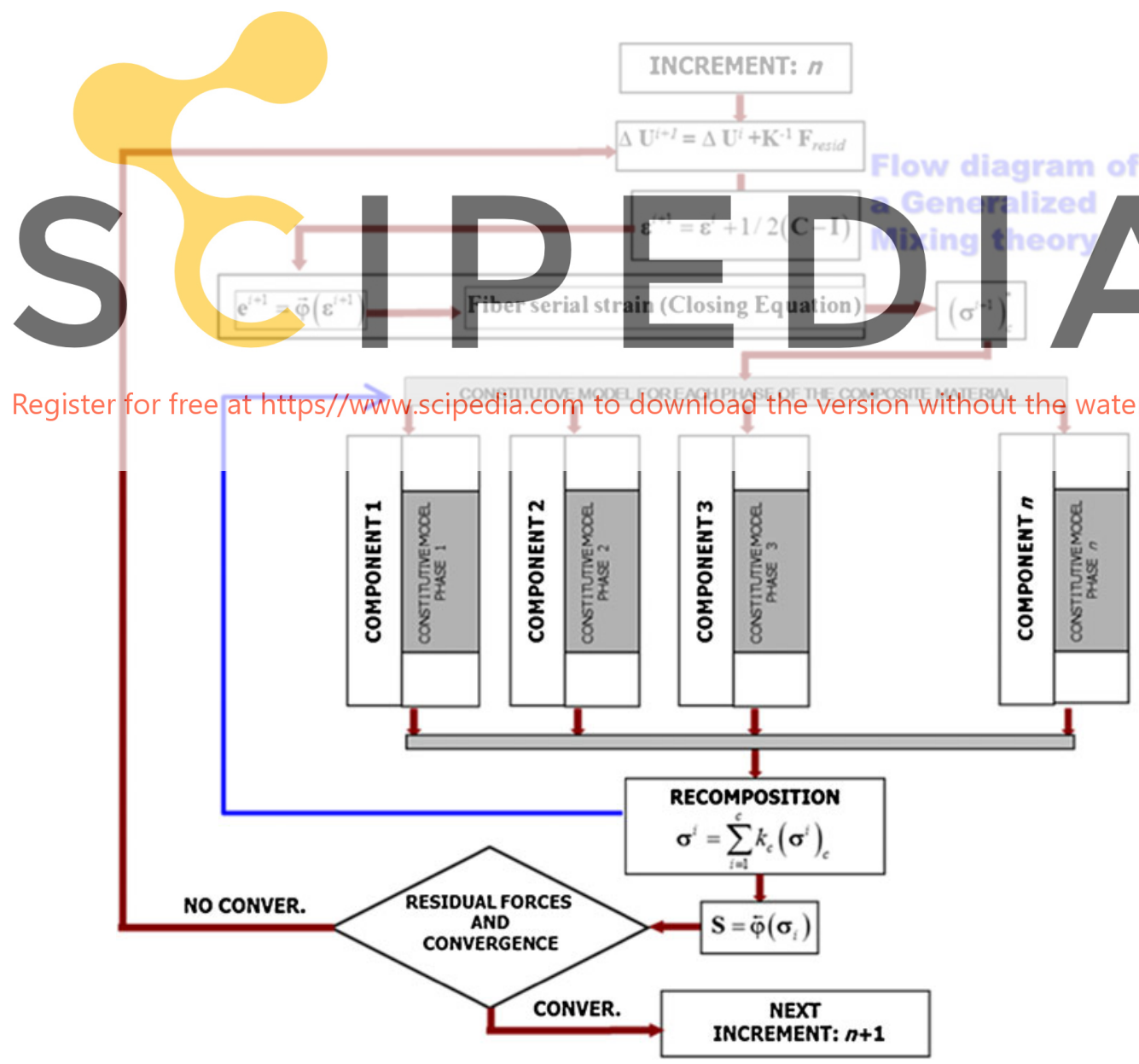

Fig. 4 Flow diagram of the Serial/Parallel mixing theory (S/P-Rule of Mixtures) 


\subsection{Serial/Parallel Mixing Theory for a Stacking Layers Composites}

Laminate composites are formed by different layers with different fiber orientations. The orientation of the fiber can be defined by the engineer or automatically by an optimization process in order to obtain the better performance of the composite according to its application. The S/P- Rule of Mixtures (RoM) formulation can be applied to each layer of the composite and, afterwards, the composite behavior is computed by combining the performance of each constituent layer. The classical mixing theory is applied to each layer to obtain the laminate behavior.

Applying the classical mixing theory onto the different layers of the laminate composite implies the assumption that all laminate are undergoing the same strain. This assumption can be considered correct, since the different laminate usually have fiber orientation distributions disposed in such a way that provide the laminate with an in-plane homogeneous stiffness.

\subsection{Local and Global Homogenized Damage Index}

In this section are defining two damage indexes (local and global) to ensure the composite laminate being within the elastic range, avoiding these two damage thresholds.

The local damage constitutive model $[11,19]$ used to set the threshold for the initiation of non-linear damage process in each point of component material integrated in the composite one and its subsequent evolution is presented in this subsection. This concept allows the new definition of a global homogenized threshold criterion of damage for the entire laminate (see

section 2.3.2), resultin material in the laminate comp

3.1 Local Damage Model
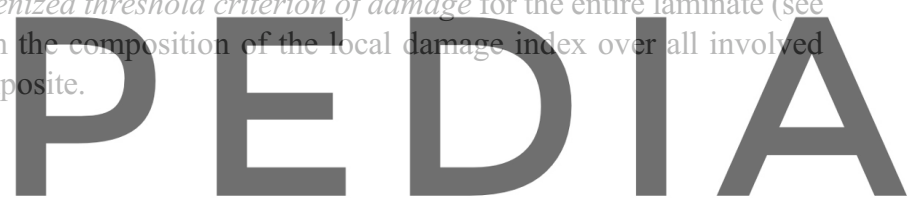
Register for free at https//www.scipedia. com to download the version without the watermark This model is used at each simple matrix material embedded in the composite one, inducing a stiffness degradation and strength reduction in the entire laminate.

The isotropic damage formulation is based on a scalar internal variable $d$ that represents the level of degradation at each simple component material. This variable are bounded between 0 and 1 , being zero for undamaged and one for completely damaged point of component material. The local damage variable $d$ is used to links the real stress tensor $\sigma$ with the effective undamaged stress tensor $\sigma_{0}$. Therefore, the relation between the damaged stress and the strain in the matrix included in each layer depends on the damage $d$ internal variable and the elastic constitutive tensor $\left(\mathbb{C}_{0}\right)$

$$
\boldsymbol{\sigma}=(1-d) \boldsymbol{\sigma}_{0}=\underbrace{(1-d) \mathbb{C}_{0}}_{\mathbb{C}_{0}^{S}}: \varepsilon=\left[\mathbb{C}_{0}: \varepsilon\right]-\left[d \mathbb{C}_{0}: \varepsilon\right]=\boldsymbol{\sigma}_{0}-\boldsymbol{\sigma}_{d}
$$

The stress condition at which damage starts and the evolution of the damage variable can be described by:

$$
F\left(\boldsymbol{\sigma}_{0} ; \boldsymbol{q}\right)=f\left(\boldsymbol{\sigma}_{0}\right)-c(d) \leq 0 \quad, \quad \text { with } \quad \boldsymbol{q} \equiv\{d\}
$$

being $F\left(\boldsymbol{\sigma}_{0} ; \boldsymbol{q}\right)$ the damage threshold function, $f\left(\boldsymbol{\sigma}_{0}\right)$ the scalar equivalent stress function and $c(d)$ the uniaxial strength evolution, depending on internal damage variable $d$. 
This formulation allows the damage onset and evolution using any limit criterion already defined in literature (von Mises, Mohr Coulomb, Drucker Prager, etc.) [8, 19], but in this paper we have used the norm of the principal stresses, with a different degradation path for tension and compression loads,

$$
f\left(\boldsymbol{\sigma}_{0}\right)=\rho \cdot\left\|\boldsymbol{\sigma}_{I}\right\|
$$

being $\sigma_{I}$ the principal stress tensor and $\rho$ a function that weights the proportion of tension and compression stresses that are applied to the material. This weight function is defined as,

$$
\rho=r_{0} \frac{\tau_{c}}{\tau_{t}}+\left(1-r_{0}\right) \quad \text { with } \quad r_{0}=\sum_{I=1}^{3}\left\langle\sigma_{I}\right\rangle / \sum_{I=1}^{3}\left|\sigma_{I}\right|
$$

being $\tau_{c}$ and $\tau_{t}$ the ultimate strength of the material in compression and tension, respectively, and $\langle\chi\rangle$ the Macaulay function.

The mechanical evolution of the damage inner variable $d$ is obtained using the damage consistency and the Kuhn-Tucker load/unload conditions [11, 19], being possible to explicitly integrate the damage internal variable to obtain:

$$
c(d)=\max \left\{\tau_{c}, \max \left\{f\left(\sigma_{0}\right)\right\}\right\} \quad \text { and } \quad d=G\left(f\left(\sigma_{0}\right)\right)
$$

The function $G$ defines the softening evolution of the material. The behavior evolution of the damage material in the present work uses an explicit exponential softening, which is defined as,
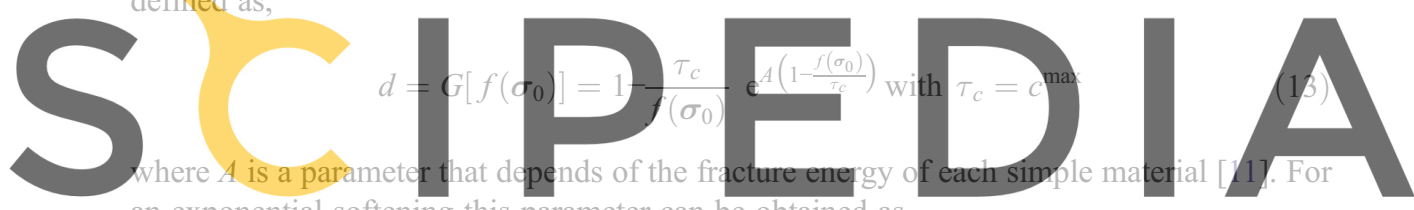

an exponential softening this parameter can be obtained as

Register for free at https//www.scipedia.com to download the version without the watermark

$$
A=\left(\frac{G_{c} \cdot C_{0}}{l_{f} \cdot \tau_{c}^{2}}-\frac{1}{2}\right)
$$

being $C_{0}$ the Young modulus of the material, $G_{c}$ the fracture compression energy of the material and $l_{f}$ the geometrically regularization parameter, called fracture length related with the characteristically size of the finite element used. The introduction of the fracture length in the formulation makes the degradation process mesh independent [11, 19].

\subsubsection{Global Homogenized Laminate Damage Index or Security Laminate Factor}

According to the Serial/Parallel mixing theory previously introduced, fibers only collaborate to the composite strengthening in longitudinal direction of the fibers. Thus, the damage on the composite material is mainly concentrated in the matrix but not in the reinforcement fibers. Thereby, when stresses in matrix reach their maximum elastic value (damage threshold), the material falls according to the damage constitutive law previously presented and, when the total fracture energy has been achieved in each point of simple component material, the material cannot support the level of the stresses and its contribution to the structure strength an stiffness disappears, starting a crack evolution/progression producing a delamination phenomenon. Also, the lack of strength in all directions is produced, except in the longitudinal fibers (because fibers do not reach the damaged threshold). Hence, this 
mechanism induces localized fracture (delamination) at constitutive level without the computational cost of breaking the mesh and re-meshing the new delaminated area.

In the case of laminates, the global composite damage variable $d^{L}$ is obtained by the homogenization of de local damage variable $d$ of each simple component materials (see section 2.3.1). This definition of homogenized laminar damage can also be interpreted as the safety laminates factor that will be used in the optimization process and will be introducing in next section. This new structural damage variable $d^{L}$ is also bounded between 0 and 1 as local damage and it is defined as,

$$
d^{L}=\left(\sum_{i=1}^{n_{G P}} V_{i}\right)^{-1} \cdot \sum_{i=1}^{n_{G P}} V_{i} d_{i}
$$

where $d_{i}$ and $V_{i}$ are the local damage variable and its Gauss point volume for each single material, $n_{G P}$ is the number of Gauss points involved in all materials included in the layers participating in the shell element.

The delamination phenomenon stops when a damaged point can provide enough shear strength to equilibrate the shear stresses that appears in the inter-laminar zone.

\subsection{Optimal Multi-Objective Algorithm Design for Laminate of Fiber-Reinforced Composites}

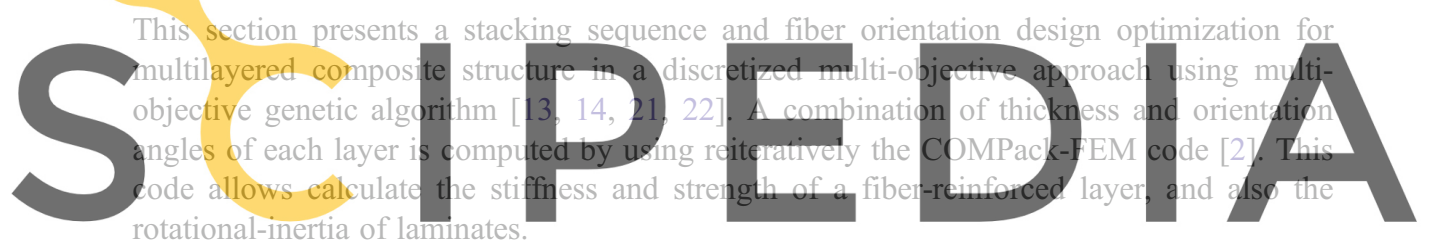

rotational-inertia of laminates.

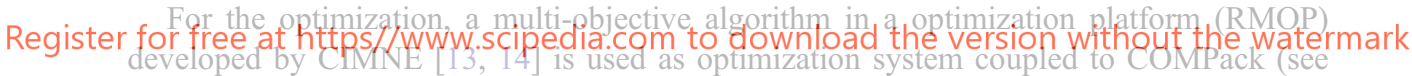

Fig. 2) to find the optimal combination of fiber orientation for multilayered composite hydrofoils which should have lower rotational-inertia, higher stiffness and affordable total cost.

Engineering design problems require a simultaneous optimization of conflicting objectives and an associated number of constraints. Unlike single objective optimization problems, the solution is a set of points known as Pareto optimal set [13, 14].

\subsubsection{Robust Multi-Objective Optimization Platform (RMOP)}

RMOP is a computational intelligence framework which is a collection of population based algorithms including a searching method based on Genetic Algorithm [21]. This algorithm uses a Pareto selection operator which ensures that the new individual is not dominated by any other solutions.

In references $[13,14]$ is shown more detail about of RMOP and the corresponding interaction modules, used in the computational code. This platform is easily coupled to any kind analysis tools, and particularly in this paper the coupling was performed with the COMPack finite element code [2], designed for the structural analysis of laminate of fiberreinforced composites (see Fig. 2). As mentioned above, COMPack-FEM code support several kinds of constitutive models and use de S/P mixing theory for the numerical 
simulation of the laminate composite material. One of the principal benefits of COMPack it's the capability of working with the constitutive model of each component material, matrix and/or fiber, considering its distribution and orientation.

\subsubsection{Numerical Optimization Problem}

The problem considers a multi-objective composite fiber orientation design optimization to find a lower rotational-inertia and stiffer multilayered symmetric balanced composite structures. The geometry, finite element mesh and loads can be seen in Figs. 1, 5 and 6.

However the proposed optimization technique is very powerful, and since the numerical model to be solved in this paper is very large, we have simplified the number of the optimization variables to solve the optimal mechanical problem of the turbine rotor, assuming constant the type of fiber (carbon fiber) and thickness of the laminate (fixed stacking) and leaving as a variable to optimize the carbon fiber angle orientation and minimization of the rotational inertia. Thus, for the complete design of the turbine rotor has been taken into account several pairs of fiber orientation, but have been chosen the three pairs more significant intermediate values for take the conclusion: Case $1:\left[ \pm 45^{0}\right]$, Case $2:\left[0^{0} / 45^{0}\right]$, Case $3:\left[45^{\circ} / 90^{\circ}\right]$. Also, the material used in the blade rotor is composed for six layers of $e=0.3 \mathrm{~mm}$, forming a laminate thickness of $t=1.8 \mathrm{~mm}$. The matrix has a density of $m_{\text {matr } i x}=1,200 \mathrm{~kg} / \mathrm{m}^{3}$, occupying a $60 \%$ of the total volume. The carbon fibers have a density of $m_{\text {fiber }}=1,800 \mathrm{~kg} / \mathrm{m}^{3}$ and involved in $40 \%$ of the total volume. The complete description of the materials properties for matrix and fibers components can be seen in Table

\section{The rotor blade solu} design optimization usi the multilayered composite minimizing its homoge
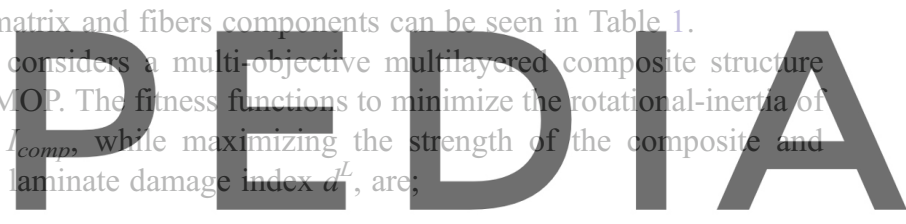

Register for free at https//www.scipedia.com to download the version without the watermark

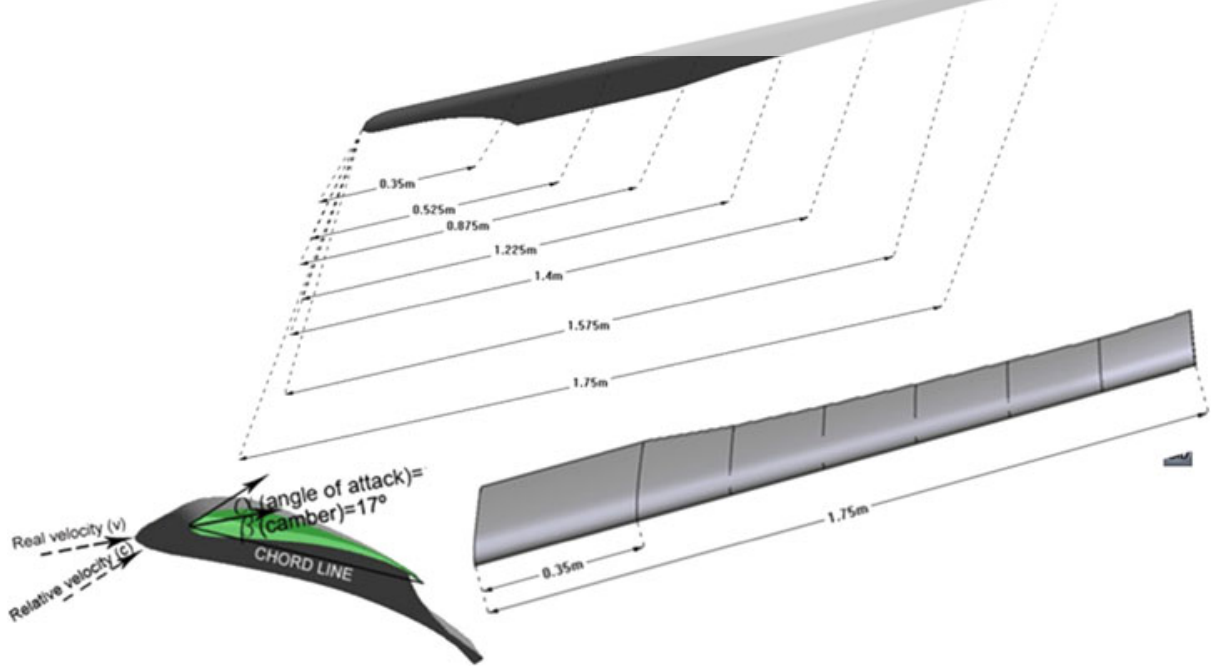

Fig. 5 Hydrofoil's dimensions and profile 

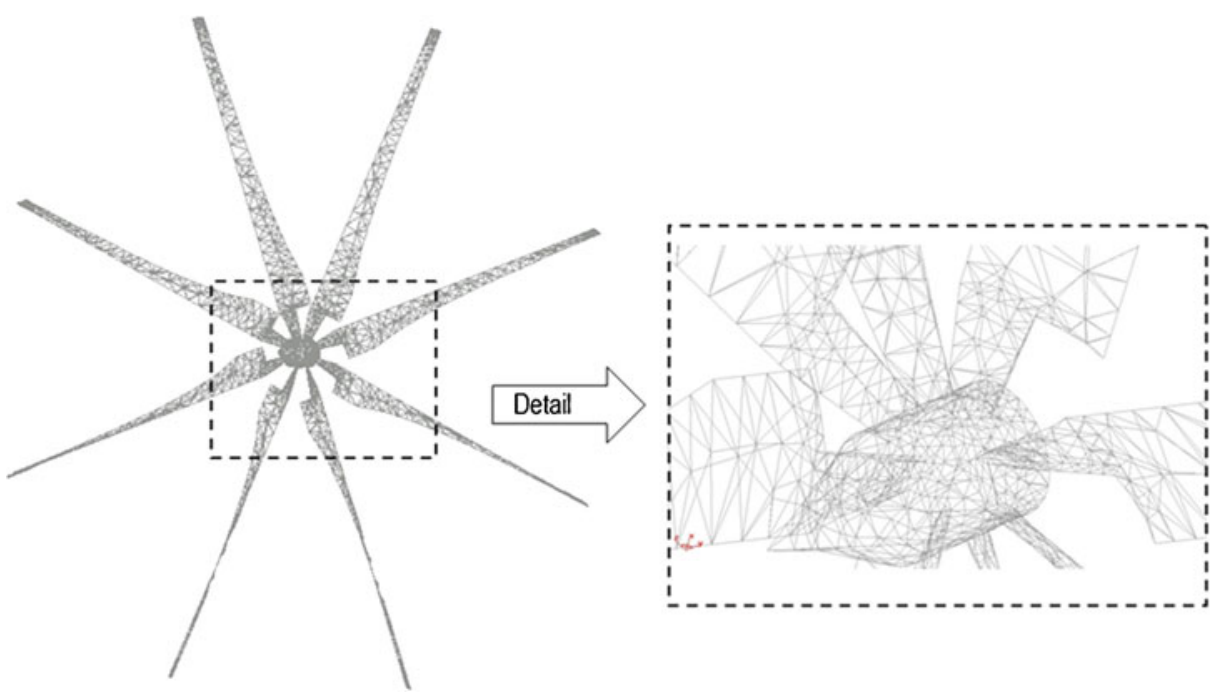

Fig. 6 Rotor's FEM mesh

$$
\begin{aligned}
& f_{1}=\min \left(I_{\text {comp }}\right)=\min \left(\sum_{i=0}^{n} I_{\text {Layer }_{i}}\right) \\
& f_{2}=\max \left(\sigma_{\text {comp }}\right)=\max \left(\sum_{i=0}^{n} \sigma_{i}\left(\theta_{j}\right)_{\text {Layer }}\right) ; \forall 0 \leq \theta_{j} \leq \pi / 2 \\
& f_{3}=\min \left(d^{L}\right)=\min \left(\left(\sum_{i=1}^{n_{G P}} V_{i}\right)^{-1} \cdot \sum_{i=1}^{n_{G P}} V_{i} d_{i}\right)
\end{aligned}
$$

Figure 7 show the solution obtained for the different composite materials, including the steel results commonly obtained for a classical turbine rotor.

Table 1 Mechanical properties of matrix and fibers of the composite material

\begin{tabular}{ll}
\hline Composite & $t=6 \times 0.3 \mathrm{~mm}=1.8 \mathrm{~mm}$ \\
\hline Matrix & $\rho=1200 \mathrm{~kg} / \mathrm{m}^{3}$ \\
& $E=4.0 \times 10^{9} \mathrm{~Pa}$ \\
& $v=0.353$ \\
& $f_{T}=610 \mathrm{MPa}$ \\
& $60 \%$ of volume fraction \\
& $\rho=1800 \mathrm{~kg} / \mathrm{m}^{3}$ \\
& $E=242.1 \times 10^{9} \mathrm{~Pa}$ \\
& $v=0.22$ \\
& $f_{T}^{\text {long }}=3800 \mathrm{MPa}$ \\
\hline
\end{tabular}



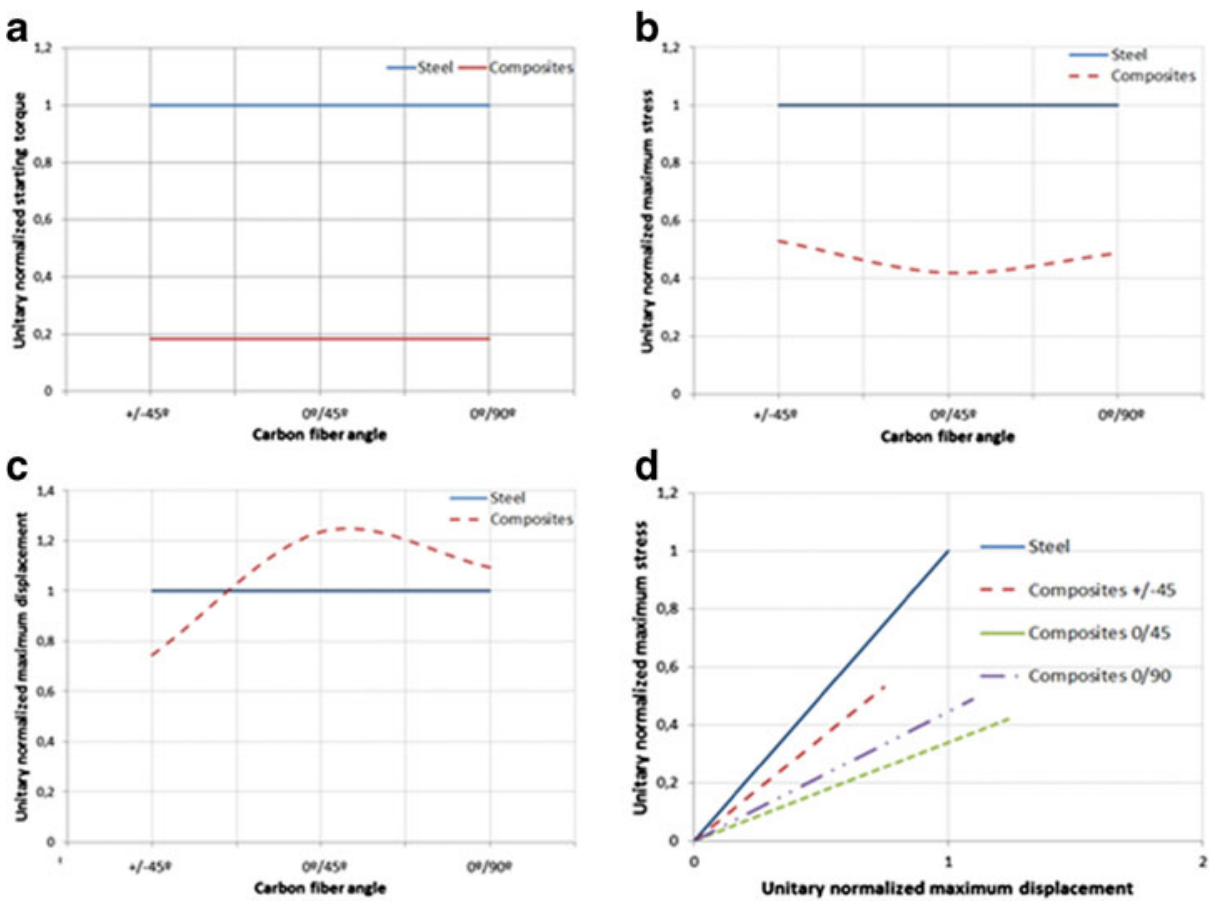

Fig. 7 Relative comparisons among the composite rotors with different fiber orientation vs. steel rotor: a "Starting torque", b "Stress field", c "Maximum displacements", d "Stiffness"

\section{Numerical Simulation of the Structural Behavior of a Rotor-Hydrofoil Water Current Turbine}

The numerical simulation of the structural behavior of the rotor of the axial flow turbine by means of finite elements method (COMPack) coupled with a multi-objective multilayered composite structure design optimization (RMOP) is presented in this section. A comparative study considering the structural response of the steel turbine rotor vs. fibers-reinforced composite material is carried out $[23,24]$. The composite material analysis is developed employing the orthotropic mixing theory previously presented, while an isotropic constitutive model is used for the steel rotor. During this analysis the fitness functions are controlled (Eq. 16).

\subsection{Geometry, Boundary Conditions and Finite Element Mesh}

The rotor is put under an axial water flow that causes a distribution of pressures on the hydrofoils. These flow pressures are obtained by KRATOS CFD finite element code and, particularly, in the leading edge of the hydrofoils of the rotor. The 8 rotor blades have a hydrodynamic profile with $15^{\circ}$ of attack angle (Fig. 5).

From the geometry of the rotor a mesh of 4100 linear shell triangular finite elements is generated with GiD (rotational-free shell triangle, [25]), with 2012 nodes (Fig. 6).

These shells structure are analyzed firstly made of steel material and then made of laminate composites material with layers of epoxy matrix reinforced by unidirectional carbon fibers. In both cases, the properties of the materials are detailed in the corresponding sections together with the respective analysis. 


\subsection{Action on the Hydrofoil's Rotor}

In this section the water pressures acting on the turbine rotor of axial axis are applied. These pressures are obtained from KRATOS CFD code for the fluvial flow at low speed river (Oller et al. [1]). This pressures cause two kinds of loads in the rotor:

- Load 1: Rotation loads on the surfaces of the hydrofoils produced by the differential pressures between the up and down surfaces of the wing. This load is obtained by the interaction with KRATOS finite element code (CFD - Computational Fluid Dynamics) to obtain the speed, correct attack angle of hydrofoils, diagrams of pressures on the wing areas, etc.

- Load 2: Axial loads caused by the directly applied pressures over the attack edge of the hydrofoil, that cause its deformation and the tensional state of the rotor, trending to break it in the perpendicular direction of the plane of the rotor. This reaction is studied and analyzed in this work through the program of finite elements COMPack (Fig. 7).

Kinematic pressures are obtained by KRATOS CFD finite element procedure which is available on the reference Oller et al. [1]. Thus, using this pressure has been obtained an applied load of $F_{\text {Rotor }}=672 N$ at the leading edges surfaces of the $n_{\text {wing }}$ hydrofoils. This load is distributed over all nodes of the blades, and is applied in one time step, mining that it is $100 \%$ of applied load in the rotor at time $t=1 \times 10^{-5} \mathrm{~s}$. This study exceeds the target of this paper and the complete fluid dynamic numerical simulation can be found in reference Oller et al. [1].

The restrictions of movement are applied to the nodes corresponding to the turbine shaft, representing the sharing points between the rotor and the axis of the turbine.

\subsection{Numerical Simulations of the Rotor Made of Steel and Composite Material}

The details of the structural behavior of each rotor conformed in steel and composite laminate are described below $[23,24]$. In the analysis corresponding to composite laminate the previously orthotropic Parallel/Serial theory of mixtures is used. An additional parametric comparison is also carried out in this case chosen from three pairs of fiber directions and stacking sequences.

Numerical simulations involves the turbine steel rotor with the following mechanical parameters: density $m=7,850 \mathrm{~kg} / \mathrm{m}^{3}$, Young modulus $E=210.0 \times 10^{6} \mathrm{~Pa}$, Poisson ratio $v=0.3$, and thickness $t=1.2 \mathrm{~mm}$; and the turbine rotor made by composite six layers, each one with $e=0.30 \mathrm{~mm}$ thickness, and three different layups: $\pm 45^{\circ}, 0^{\circ}-90^{\circ}$ and $0^{\circ}-45^{\circ}$, (see mechanical properties of components in Table 1), are used in the analysis comparison.

It can be observed after the $1 \mathrm{~s}$ applied load, that the minimum stress, $\sigma=10,622 \mathrm{~Pa}$ (Table 2 and Fig. $7 \mathrm{~b}$ ), corresponds to the non-orthogonal $0^{\circ}-45^{\circ}$ layup configuration, which occurs in the blades near to the shaft junction (Fig. 8). Figure 9 shows the displacements in the rotor.

Table 2 Comparison between the four most significant rotors

\begin{tabular}{lcccc}
\hline Type of rotor & $\mathrm{T}[\mathrm{mm}]$ & $\begin{array}{l}\text { Starting } \\
\text { torque }[\mathrm{Nm}]\end{array}$ & $\begin{array}{l}\text { Maximum } \\
\text { stress }[\mathrm{Pa}]\end{array}$ & $\begin{array}{l}\text { Maximum } \\
\text { displacement } \\
{[\mathrm{m}]}\end{array}$ \\
\hline Steel & 1.8 & 217 & $25.324,00$ & $2,21 \mathrm{E}-03$ \\
Comp. $\pm 45^{\circ}$ & $6 \times 0.3=1.8$ & 40 & $13.397,00$ & $1,65 \mathrm{E}-03$ \\
Comp. $0^{\circ} / 45^{\circ}$ & $6 \times 0.3=1.8$ & 40 & $10.622,00$ & $2,73 \mathrm{E}-03$ \\
Comp. $0^{\circ} / 90^{\circ}$ & $6 \times 0.3=1.8$ & 40 & $12.342,00$ & $2,42 \mathrm{E}-03$ \\
\hline
\end{tabular}




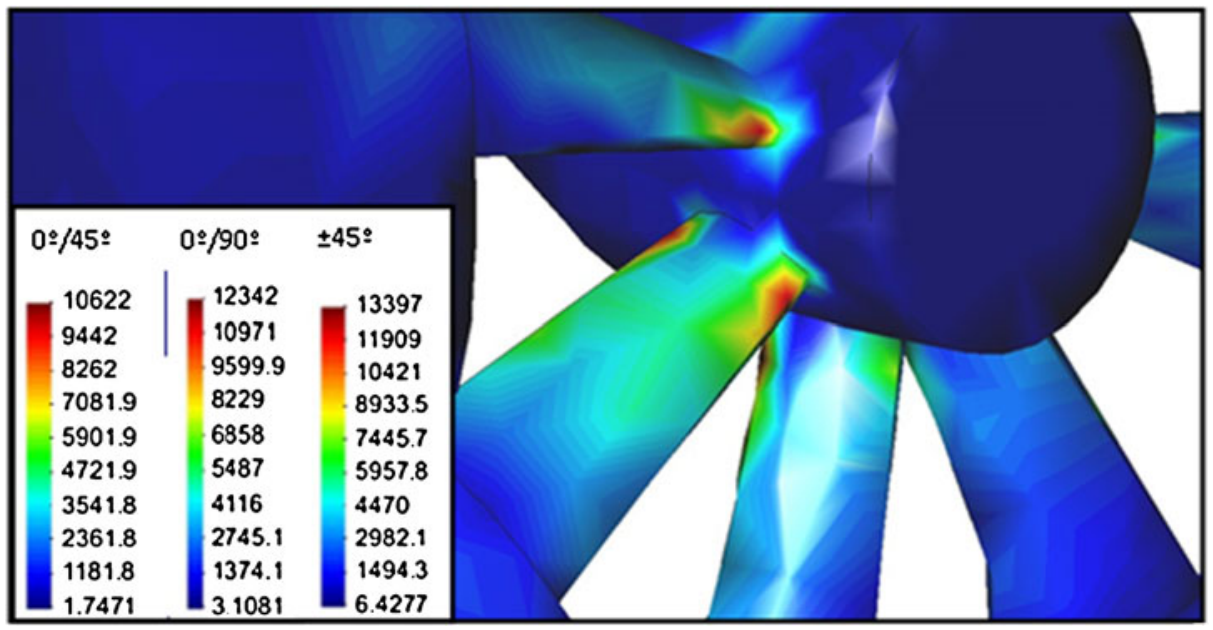

Fig. 8 Places of the composite laminate rotor with the profile stress [MPa]distribution

\section{Rotational Inertia}

In WCT axial turbines, the task of reducing the rotational inertia of the rotor is as important as possible. This will lower resistance to rotation in front of the river speed changes, allowing more flexibility in starting and stopping of the turbine rotation. With this aim, the values of the rotational inertia of the turbine rotor are shown below.

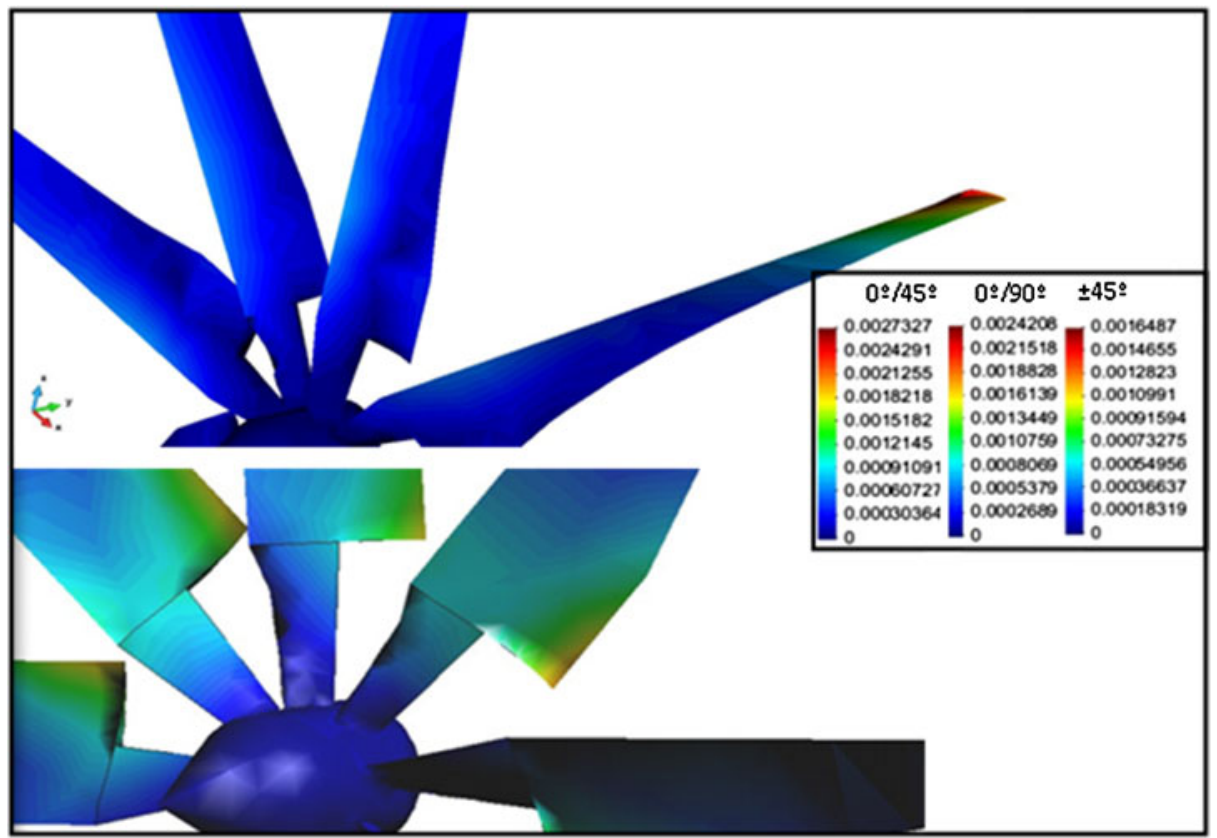

Fig. 9 Places of the composite laminate rotor with the profile displacements [m]distribution 
Inertia of the Steel Rotor For $1.8 \mathrm{~mm}$ thickness layer steel, and a $m_{\text {steel }}=7,850 \mathrm{~kg} / \mathrm{m}^{3}$ of density, and a $V_{\text {steel }}=0.014 \mathrm{~m}^{3}$ of rotor's volume, the mass rotor is $M_{\text {steel }}=108 \mathrm{Kg}$, the rotational inertia is $I_{\text {steel }}=1736 \mathrm{Kg} \mathrm{m}$, and the starting torque results equal to $T_{\text {steel }}=217 \mathrm{~N} \mathrm{~m}$.

Inertia of the Composite Rotor Taking into account a $1.8 \mathrm{~mm}$ thickness layer composite, and a density matrix of $m_{\text {matrix }}=1200 \mathrm{~kg} / \mathrm{m}^{3}$ (participating in a volume fraction of the $60 \%$ of the composite material), and a density fiber of $m_{f i b e r}=1800 \mathrm{~kg} / \mathrm{m}^{3}$ (participating in a volume fraction of the $40 \%$ of the composite material). In this case the mixing theory gives a density for the composite of $m_{\text {comp }}=1440 \mathrm{~kg} / \mathrm{m}^{3}$, and a volume of the rotor of $V_{\text {comp }}=0.014 \mathrm{~m}^{3}$, resulting a mass rotor of $M_{\text {comp }}=20 \mathrm{Kg}$, the rotational inertia of $I_{c o m p}=318 \mathrm{Kg} \mathrm{m}^{2}$, and the machine starting torque results equal to $T_{\text {comp }}=40 \mathrm{Nm}$. This latter value is 5.5 times less than the steel rotor.

\section{Conclusions}

In this paper an integrated structural design of a composite rotor hydrofoil is presented. It also introduces a new index of structural damage to control composite elastic threshold. As a result of this formulation, we can see that the " $0 / 45^{\circ}$ " laminate composite rotor works with nearly $40 \%$ level of stresses of the steel rotor. The " $\pm 45^{\circ}$ " composite laminate rotor and the " $0 \% / 90^{\circ}$ " composite laminate also work at less stresses than steel rotor (Table 2 and Fig. $7 \mathrm{~b}$ ).

All composite laminate rotors have less stiffness than the steel rotor, but particularly the composite with fibers oriented to " $\pm 45^{\circ}$ " has a high stiffness and near to the steel value (see its relative comparison, Fig. $7 d$ ). However, the composite laminate of " $0 \% / 45^{\circ}$ " has a much lower stiffness than the other (Fig. 7d), but is enough for this machine requirements, as its maximum displacement is tolerable in these work functions (see its relative comparison, Fig. 7c).

The reduced starting torque of composite laminate rotor is a big advantage during the operating work of the water turbine, since composites have 5.5 times less starting torque than the steel rotor (Fig. 7a). It means a machine with better performances at low water flux velocities, easier to ship, handle, repair, start, etc.

Concluding, the composite laminated rotor of fibers oriented to " $\pm 45^{\circ}$ " is the best suited material for this function, since it has a very low rotational inertia (18.3\% of the steel rotor. See Fig. 7a), a maximum working stress a $47 \%$ lower than the steel rotor (Fig. 7b), and finally has a good stiffness ( $53 \%$ of the value corresponding to the steel rotor. See Fig. $7 d$ ) and consistent with a relatively low maximum displacement (Fig. 9c).

Acknowledgments This work has been supported by the Spanish Government through the Ministry of Science and Innovation (AECID (ref. A/024063/09) Spain; Barcelona Tech (Technical University of Catalonia UPC), Spain; International Center for Numerical Method in Engineering (CIMNE), Spain; CIMNEClassrooms of National University of Salta, Argentina; National Scientific and Technical Research Council (CONICET), Argentina, and University of Salta Research Council (CIUNSa), Argentina). All this support is gratefully acknowledged.

\section{References}

1. Oller, S.A., Coussirat, Miguel, Nallim, Liz G.: Diseño fluido dinámico de un rotor de turbina de paso con flujo axial (WCT: water current turbine), mediante el uso de métodos numéricos (CFD). Tercer Congreso Argentino de Ingeniería Mecánica (III CAIM). Buenos Aires, Argentina, (2012) 
2. COMPack: CIMNE and Quantech-ATZ. Innovative Finite Element Code for non linear analysis of composite structures, Explicit finite element, code developed by CIMNE \& Quantech ATZ. www.cimne.com, www.quantech.es, (2008-now)

3. Rastellini, F., Oller, S., Salomón, O., Oñate, E.: Composite material non-linear modelling for long fibre-reinforced laminates. Continuum basis, computational aspects and validations. Comput. Struct. 86, 879-896 (2008)

4. Car, E., Oller, S., Oñate, E.: A large strain plasticity for anisotropic materials-composite material application. Int. J. Plast. 17(11), 1437-1463 (2001)

5. Martinez, X., Rastellini, F., Flores, F., Oller, S., Oñate, E.: Computationally optimized formulation for the simulation of Composite materials and delamination failures. Compos. Part B. Eng. Part B 42(2011), 134-144 (2010)

6. Kratos Multi-Physics: CIMNE and Quantech-ATZ. General Finite Elements Multiphisics code. http:// www.cimne.com/kratos/, (2005-now)

7. Ferziger, J., Perić, M.: Computational methods for fluid dynamics. Springer, Berlin (2002)

8. Zienkiewicz, O.C., Taylor, L.R.: The finite element method. McGraw-Hill, London (1991)

9. Oller, S., Car, E., Lubliner, J.: Definition of a general implicit orthotropic yield criterion. Comput. Methods Appl. Mech. Eng. 192(7-8), 895-912 (2003)

10. Martinez, X., Oller, S., Barbero, E.: Study of delamination in composites by using the serial/parallel mixing theory and a damage formulation. Composites 2007, U. Porto. 12th to 14th September/2007. (2007)

11. Oliver, J., Cervera, M., Oller, S., Lubliner, J.: A Simple Damage Model For Concrete, Including Long Term Effects. Second International Conference on Computer Aided Analysis and Design of Concrete Structures. vol. 2, pp. 945-958. Zell Am See, Austria. Viena (1990)

12. Martinez, X., Oller, S.: Numerical simulation of matrix reinforced composite materials subjected to compression loads. Arch. Comput. Methods 16(4/Dic/2009 de 2009), 357-397 (2009)

13. Lee, D.S., Morillo, C., Oller, S., Bugeda, G., Onate, E.: Robust design optimisation of advance hybrid (fiber-metal) composite structures. Compos. Struct. 99, 181-192 (2013)

14. Lee, D.S., Morillo, C., Bugeda, G., Oller, S., Onate, E.: Multilayered composite structure design optimization using distributed/parallel multi-objective evolutionary algorithms. Compos. Struct. 94(3), $1087-1096(2012)$

15. Trusdell, C., Toupín, R.: The classical field theories, Handbuch der physic iii, Ith edn. Springer, Berlin (1960)

16. Car, E., Oller, S., Oñate, E.: An anisotropic elasto-plastic constitutive model for large strain analysis of fiber reinforced composite materials. Comput. Methods Appl. Mech. Eng. 185(2-4), 245-277 (2000)

17. Sánchez-Palencia, E.S.: Homogenization techniques for composite media. Chapter: Boundary layers and edge effects in composites, pp. 121-192. Springer, Berlin (1987)

18. Oller, S., Miquel, J., Zalamea, F.: Composite material behavior using a homogenization double scale method. J. Eng. Mech. 131(1), 65-79 (2005)

19. Lubliner, J., Oliver, J., Oller, S., Oñate, E.: A plastic damage model for concrete. Int. J. Solids Struct. 25(3), 299-326 (1989)

20. Oller, S., Oñate, E., Oliver, J., Lubliner, J.: Finite element non-linear analysis of concrete structures using a plastic-damage model. Eng. Fract. Mech. 35(1-3), 219-231 (1990)

21. Deb, K.: Multi-Objective Optimisation using Evolutionary Algorithms, Wiley (2003)

22. Gen, M., Cheng, R.: Genetic Algorithm and Engineering Design, firstth edn. John Wiley and Sons. Inc, New York (1997)

23. Oller, S.A., Nallim, L.G., Oller, S.H.: Diseño de un rotor de turbina hidroeléctrica conformada en materiales compuestos de matriz reforzada con fibras de carbono. II Congreso de Ingeniería Mecánica, San Juan (2010)

24. Oller, S.A., Nallim, L.G., Oller, S.H.: Estudio Comparativo de la Respuesta Estructural de Álabes de Turbina de Material Compuesto. Mecánica Computacional. Advanced Analysis in Steel and Composite Structures. Buenos Aires, Argentina. XXIX(75), (2010)

25. Flores, F.G., Onate, E.: A rotation-free shell triangle for the analysis of kinked and branching shells. Int. J. Numer. Methods Eng. 69(7), 1521-1551 (2007) 